\title{
Facile TEMPO Immobilization onto Poly(acrylic acid)-Modified Magnetic Nanoparticles: Preparation and Property
}

\author{
Guohui Huang, ${ }^{1}$ Xiaoxuan Liu, ${ }^{1}$ Yiling Bei, ${ }^{2}$ and Huiqing $\mathrm{Ma}^{2}$ \\ ${ }^{1}$ School of Materials and Energy, Guangdong University of Technology, Guangzhou, Guangdong 510006, China \\ ${ }^{2}$ School of Chemistry and Chemical Engineering, Shandong University, Jinan, Shandong 250100, China \\ Correspondence should be addressed to Xiaoxuan Liu; p-xxliu@gdut.edu.cn and Yiling Bei; beiyiling@sdu.edu.cn
}

Received 20 March 2017; Revised 11 April 2017; Accepted 19 April 2017; Published 30 May 2017

Academic Editor: Mehdi Salami-Kalajahi

Copyright (c) 2017 Guohui Huang et al. This is an open access article distributed under the Creative Commons Attribution License, which permits unrestricted use, distribution, and reproduction in any medium, provided the original work is properly cited.

\begin{abstract}
Adding catalysts to magnetic polyvalent supports facilitating catalyst recycling and recovery seems feasible. Polymer-modified magnetic nanocomposites for organocatalyst immobilization are a plausible approach to this technology. Here, we present facile and efficient method for 2,2',6,6'-tetramethylpiperidinyl-1-oxy (TEMPO) immobilization onto polymer-modified magnetic nanoparticles under mild reaction conditions. Poly(acrylic acid) was chosen to graft from magnetic nanoparticle through a simple inverse emulsion polymerization technique. The resulting poly(acrylic acid) magnetic nanocomposite is an ideal material to immobilize the organocatalyst 4-hydroxy-2,2' $, 6,6^{\prime}$-tetramethylpiperidinyl-1-oxy (H-TEMPO) via an esterification reaction with pendant carboxyl group on the polymer chain. Instrumental analysis confirmed that poly(acrylic acid) chain was grafted on the silica-coated magnetic particles by this simple method while maintaining their magnetic properties; elemental analysis indicated that TEMPO was efficiently immobilized onto the polymer chain. The catalysis tests under both Anelli and Minisci system showed that the nanocomposite catalyst exhibits proper selectivity and activity for the alcohol/aldehyde transformation. Recycling experiments showed that stability and reusability of the nanocomposite catalyst were satisfying.
\end{abstract}

\section{Introduction}

Green catalysis for synthetic protocols and reactions is a fascinating and a major challenge in sustainable chemistry. There has been an explosion of interest in development of various methods to improve catalyst efficiency [1]. One popular route is to immobilize catalyst to enable the reuse of catalyst and simplify the purification process [2]. Immobilizing catalyst onto different support materials not only improves catalyst productivity but also prevents hazardous catalysts from leaking into the environment [3].

Recently, different types of catalyst support materials such as polymer supports [4-10], ionic liquid supports [10-12], inorganic supports [13-18], metal organic frame supports [19], and nanocomposite supports [20-22] have been invented for immobilizing catalysts on beads, surfaces, and membranes, and so forth [23]. Of these, magnetic iron oxide nanocomposites have been the most widely used support material [2] because they offer enormous surface area with more binding sites; this reduces the disadvantages of heterogeneous catalysis [24].
Typically, organocatalyst TEMPO can utilize harmless and friendly oxidants $[25,26]$ such as molecular oxygen, hydrogen peroxide, or air for alcohols/aldehydes or ketones stoichiometric transformation. Immobilizing TEMPO on magnetic nanocomposites heightens catalyst-recycling efficiency; however magnetic nanoparticles are inorganic, and it is challenging to directly immobilize organic catalysts. This can lead to low catalyst loading efficiency. Currently, different methods have been successfully used to immobilize TEMPO on magnetic nanoparticles, such as "click" chemistry [27, 28], amine reduction [29-31], and encapsulation and polymer/ nanoparticle blends [32]. The design and synthesis of magnetic nanoparticles with polymer chains on its surface [33] for specific catalyst immobilization not only improves immobilization efficiency but also avoids the use of potential harmful substances such azides or cyanoborohydrides that are employed in previous works [27-32]. The polymer chains on the magnetic nanoparticles surface offer pendant functional groups for organocatalyst anchoring reaction. 
Here, we synthesized magnetic iron oxide nanoparticles with surface vinyl groups and employed reverse emulsion polymerization for surface polymerization of acrylic acid on the nanoparticle. This approach combines a poly(acrylic acid) chain grafted from magnetic iron oxide nanoparticles and forms an ideal support material for 4-hydroxy-2,2',6,6 ${ }^{\prime}$-tetramethylpiperidinyl-1-oxy (H-TEMPO). This novel method uses simple approaches and avoids potential harmful substances [27-31]; hence it is a facile and green approach to prepare iron oxide-based magnetic nanocomposite materials with efficient immobilization of TEMPO. The product was investigated as catalyst for alcohols/aldehydes or ketone transformation under both the Anelli [34] and Minisci [35] protocols.

\section{Experimental}

2.1. Raw Materials. All reagents and solvents were of analytical grade and used as received without further purification unless otherwise noted. The organic catalyst 4-hydroxy2,2',6,6'-tetramethylpiperidinyl-1-oxy (H-TEMPO) and trichlorovinylsilane were purchased from Energy Chemical (China). Dicyclohexylcarbodiimide was purchased from J\&K Scientific. Monomer acrylic acid was carefully distilled to remove inhibitor and preserved in refrigerator before use.

2.2. Characterization. Elemental analysis was performed on a CE instruments EA 1110 elemental analyzer. The infrared spectroscopy of all products was recorded in the range $4000-400 \mathrm{~cm}^{-1}$ with Bruker Tensor 27 FT-IR spectrometer. Transmission electron microscopy (JEM 2100) was operated at $200 \mathrm{kV}$ for morphological analysis. Magnetic properties of synthesis materials were studied with vibrating sample magnetometer (9600 VSM, BOJ Electronics, Troy, MI) at RT. Gas chromatography analysis was measured on Agilent GCMS chromatograph (model type: 7890A-5975C).

2.2.1. Preparation of Silica-Coated Magnetite Nanoparticles $\left(\mathrm{Si}-\mathrm{Fe}_{3} \mathrm{O}_{4}\right)$. Bare iron oxide $\left(\mathrm{Fe}_{3} \mathrm{O}_{4}\right)$ nanoparticles were prepared by coprecipitation method with minor modifications [36]. In a typical process, ferric chloride hexahydrate (11.70 g) and ferrous chloride tetrahydrate $(4.28 \mathrm{~g})$ were dissolved in $120 \mathrm{~mL}$ deionized water at room temperature under nitrogen inert atmosphere with vigorous stirring until the salts were completely dissolved; the temperature was then raised to $60^{\circ} \mathrm{C}$. Next, aqueous ammonia $(25 \%, 80 \mathrm{~mL})$ was quickly poured into the solution and the temperature was increased to $90^{\circ} \mathrm{C}$ with continual stirring for 30 minutes with a mechanical stirrer. Bare $\mathrm{Fe}_{3} \mathrm{O}_{4}$ nanoparticles were carefully collected with a neodymium magnet and washed with deionized water until they were neutralized.

Bare $\mathrm{Fe}_{3} \mathrm{O}_{4}$ nanoparticles from the previous step were directly suspended in a solution of ethanol and deionized water $(\mathrm{V} / \mathrm{V}=4 / 1,200 \mathrm{~mL})$ and sonicated for $15 \mathrm{~min}$. Next, $5 \mathrm{~mL}$ of tetraethoxysilane (TEOS) was added slowly to the mixture and sonicated for $10 \mathrm{~min}$. The reaction mixture was transferred to a single-neck flask equipped with a mechanical stirring device. Aqueous ammonia $(25 \%, 18 \mathrm{~mL})$ was added within $10 \mathrm{~min}$. The mixture reacted at room temperature for
$12 \mathrm{~h}$. Iron oxide nanoparticles coated with silica $\left(\mathrm{Fe}_{3} \mathrm{O}_{4} @\right.$ $\mathrm{SiO}_{2}$ ) were collected and washed three times with water and ethanol using a neodymium magnet and then dried for 24 hours.

\subsubsection{Preparation of Magnetic Nanoparticles Coated with} Vinyl Group (Vinyl-MNPs). Dry Si-Fe ${ }_{3} \mathrm{O}_{4}$ powder (3.0 g) and $6 \mathrm{~mL}$ of trichlorovinylsilane were suspended in $150 \mathrm{~mL}$ dry toluene under inert atmosphere followed by sonication of the mixture for 30 minutes. The products reacted on a $105^{\circ} \mathrm{C}$ oil bath and for 10 hours. The product powder was separated using a neodymium magnet, washed with ethanol three times and dried under vacuum.

2.2.3. Surface Polymerization Acrylic Acid on Vinyl-MNPs to Prepare Poly(acrylic acid)@ $\mathrm{SiO}_{2} @ \mathrm{Fe}_{3} \mathrm{O}_{4}$ (PAA-MNPs). We prepared a mixture of vinyl-MNPs $(0.2 \mathrm{~g})$ and acrylic acid $(3.0 \mathrm{~g})$ in a $50 \mathrm{~mL}$ beaker followed by $10.0 \mathrm{~mL}$ of deionized water. This was sonicated for 20 minutes. The suspension was slowly added dropwise to Span-80 cyclohexane solution (20 g Span-80 in $250 \mathrm{~mL}$ cyclohexane) with stirring. This was stirred for another hour to preemulsify under an inert atmosphere. The temperature was adjusted to $60^{\circ} \mathrm{C}$ for $15 \mathrm{~min}$, and then the initiator $2,2^{\prime}$-azobisisobutyronitrile (AIBN, 0.1g) was added. To ensure complete conversion of the monomers, the reaction proceeded for another 4 hours. Methanol was added for demulsification after the reaction was over. The nanocomposite product was refluxed in ethanol for 2 hours before using a neodymium magnet to collect and wash with methanol; the product was then dried under vacuum.

2.2.4. Immobilization of TEMPO on PAA-MNPs Magnetic Nanoparticles (TEMPO-MNPs). The PAA-MNPs (1g) and $\mathrm{H}$-TEMPO (2 g) and N,N' ${ }^{\prime}$-dicyclohexylcarbodiimide (DCC, 1.2 equivalent to H-TEMPO) were suspended in dry THF $(100 \mathrm{~mL})$. The reaction mixture was refluxed for 8 hours. The target product was collected using a neodymium magnet and washed three times with ethanol and dried under vacuum.

\subsubsection{Determination of Catalysis Activity and Recycling Test}

General Procedure for Catalysis Activity Test under Minisci Protocol. Alcohol (20 mmol), TEMPO-MNPs powder $(200 \mathrm{mg})$, $\mathrm{Mn}\left(\mathrm{NO}_{3}\right)_{2}(120 \mathrm{mg}, 50 \%$ aqueous solution $), \mathrm{Co}\left(\mathrm{NO}_{3}\right)_{2}(120 \mathrm{mg}$, $50 \%$ aqueous solution), and $208.3 \mathrm{mg}$ internal standard (acetophenone) in $15 \mathrm{~mL}$ of $\mathrm{CH}_{3} \mathrm{COOH}$ were stirred in a twonecked flask at $40^{\circ} \mathrm{C}$. The atmosphere of flask was then replaced with pure oxygen (balloon filled). The resulting suspension was stirred at $50^{\circ} \mathrm{C}$ under this normal atmosphere pressure. Samples were regularly removed for GC-MS analysis.

General Procedure for Catalysis Activity Test under Anelli Protocol. A $25 \mathrm{~mL}$ reaction flask was charged with alcohol (20 mmol), $1.0 \mathrm{~mL} \mathrm{KBr}$ solution (1.0 M) $10 \mathrm{~mL}$ dichloromethane, $208.3 \mathrm{mg}$ internal standard (acetophenone), and $150 \mathrm{mg}$ supported TEMPO-MNPs material. The resulting suspension was stirred in an ice-water bath for $10 \mathrm{~min}$ before gradual addition of $\mathrm{NaClO}(0.35 \mathrm{M}, \mathrm{pH} 8.7,1.2$ eq to alcohols). 


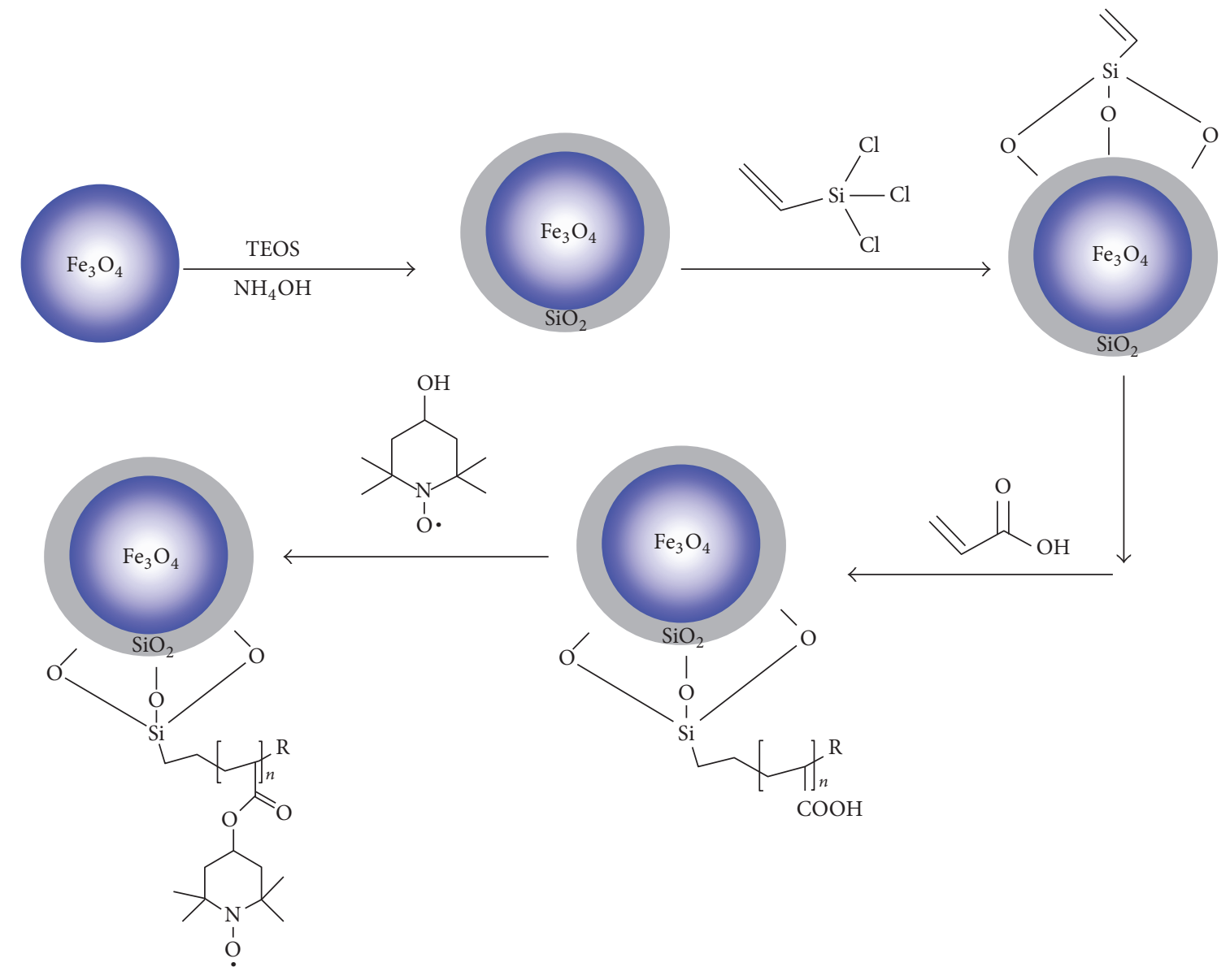

SCHEME 1: Synthetic procedure.

Samples were regularly removed with an external magnet followed by $\mathrm{Et}_{2} \mathrm{O}(3 \times 5 \mathrm{~mL})$ extraction and direct GC-MS analysis.

Gas chromatography (GC) results for all catalysis experiments were included in the supporting information (see Supplementary Material pages 1 and 2 available online at https:// doi.org/10.1155/2017/9621635).

\subsubsection{Procedure for Catalysis Recycling Property of Supported} TEMPO-MNPs Material. Recycling of supported TEMPOMNPs materials used a Minisci oxidation method without an internal standard. After the oxidation reaction was complete, the TEMPO-MNPs were magnetically separated and washed subsequently with ethyl dichloromethane, acetone, and $\mathrm{H}_{2} \mathrm{O}$ and directly used for subsequent catalysis without further purification. A new reaction was then performed with fresh reactants under the same conditions.

Gas chromatography-mass spectrometry (GC-MS) results of recycling test were included in supporting information (see Supplementary Material page 3).

\section{Results and Discussion}

The synthetic route for the nanocomposite materials and TEMPO anchoring procedure are illustrated in Scheme 1.
The key step was polymerizing acrylic acid onto the magnetic particle surface. In the first step, relatively monodisperse bare $\left(\mathrm{Fe}_{3} \mathrm{O}_{4}\right)$ nanoparticles were synthesized by coprecipitation of iron (II) and iron (III) salts under basic solution at $90^{\circ} \mathrm{C}$ using Huang et al.s method [36]. There are diverse routes for obtaining magnetic iron oxide particles. The simplest and most efficient chemical pathway is probably coprecipitation. Fortunately, particles prepared by this method contain extra surface hydroxyl (-OH) groups for chemical modification. Tetraethyl orthosilicate (TEOS) was used to coat the bare magnetic particles. The silica shell prevents $\mathrm{Fe}_{3} \mathrm{O}_{4}$ nanoparticle self-oxidation and leaching of ferric ions from the material core under severe conditions. The outer layer of the shell also provides many more $\mathrm{Si}-\mathrm{OH}$ units for derivatization with silane coupling agent [37]. In the third step, the silica-coated $\mathrm{Fe}_{3} \mathrm{O}_{4}$ nanoparticles were dispersed in dry toluene and a trichlorovinylsilane mixture solution and vigorously stirred. This resulted in a surface containing vinyl groups. The vinylcoated nanocomposite particles were further modified with acrylic acid via an inverse emulsion polymerization resulting in polymer-magnetic support material (Scheme 2).

Reverse emulsion polymerization takes place in latex particles, in which the surface containing vinyl group nanocomposite particles was confined. Vinyl silane compounds are traditionally used in the coating industry to improve adhesiveness on glass product; hence, surface vinyl groups on 


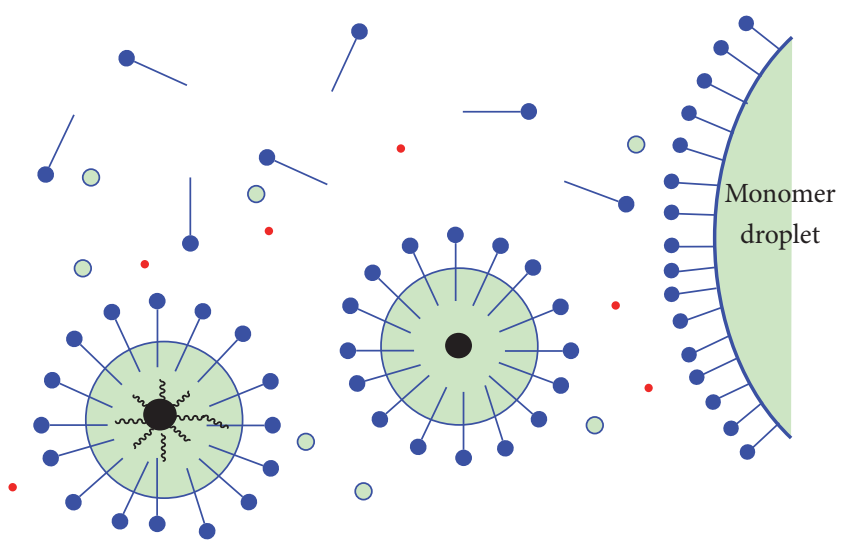

$\begin{array}{lll}\text { man Poly(acrylic acid) chain } & \mathrm{Fe}_{3} \mathrm{O}_{4} \\ \text { - Initiator molecule } & \text { Emulsifier } \\ 0 \text { Monomer droplet } & \text { P Polymer chain grafted nanoparticle }\end{array}$

SCHEME 2: Schematic illustration for the inverse emulsion polymerization.

nanoparticle surrounded by the monomer could react with radical reactive center to form an acrylic acid polymer chain. Versus bulk polymerization and suspension polymerization, this synthesis procedure can efficiently prevent acrylic acid from crosslinking to form an insoluble magnetized gel. This novel support material has many carboxylic acid groups on the surface because of every side chain of poly(acrylic acid) (PAA) and is well-suited for TEMPO immobilization. The anchoring of TEMPO onto magnetic supports was easily and mildly conducted using $\mathrm{N}, \mathrm{N}^{\prime}$-dicyclohexylcarbodiimide (DCC)/4-dimethyl-amino-pyridine (DMAP) and esterification catalysis in tetrahydrofuran solution.

3.1. FT-IR Analysis and Elemental Analysis. FT-IR spectroscopy was used to verify the conversion of organic functional groups on the particle surface. The inorganic nature of the iron oxide nanoparticle changed the polymer's composite nature. FT-IR data at each modification step clearly revealed this shift in the inorganic to organic composite. The FT-IR spectra of PAA/SiO $2 / \mathrm{Fe}_{3} \mathrm{O}_{4}$ (Figure 1(4)) showed characteristic saturated hydrocarbons stretching vibration absorption (3000 2900 $\mathrm{cm}^{-1}, \mathrm{C}-\mathrm{H}$ stretching) and a band at $1710 \mathrm{~cm}^{-1}$ (carbonyl). These data confirmed PAA segment bonding to the surface of magnetic nanoparticles.

After esterification, the anchoring of TEMPO onto the polymer chains of magnetic supports enhanced the organic absorption peaks. Comparison before and after the anchoring of TEMPO (Figure $1(4,5)$ ) shows a red shift in the carboxyl group peak $\left(1710 \mathrm{~cm}^{-1}-1718 \mathrm{~cm}^{-1}\right)$ further indicating that the TEMPO was successfully immobilized onto the magnetic carrier.

Elemental analysis confirmed TEMPO loading was approximately $2.5 \mathrm{mmol} / \mathrm{g}$ (elemental results were provided in Table 1 and catalyst loading was calculated according to nitrogen content). This result also indicated that TEMPO was simply and conveniently attached to the particle surface

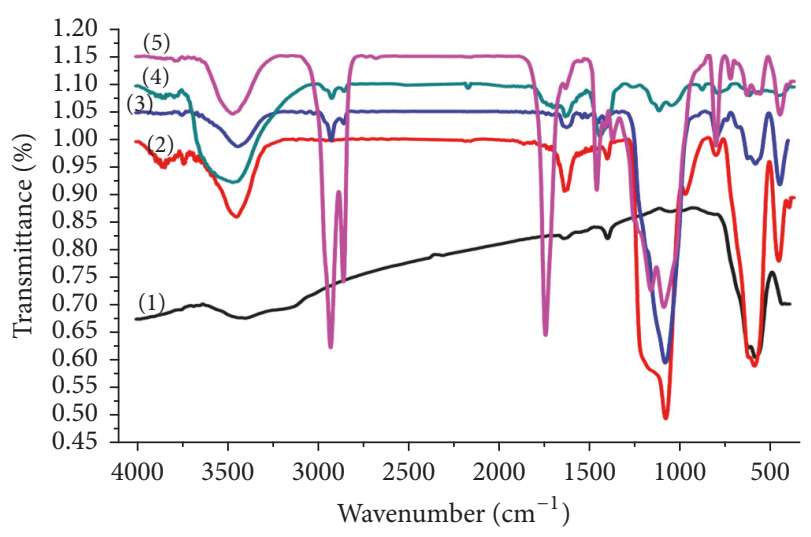
(1) $\mathrm{Fe}_{3} \mathrm{O}_{4}$
(4) $\mathrm{PAA}-\mathrm{Fe}_{3} \mathrm{O}_{4}$
(2) $\mathrm{Si}_{3}-\mathrm{Fe}_{3} \mathrm{O}_{4}$
(5) TEMPO- $\mathrm{Fe}_{3} \mathrm{O}_{4}$
(3) Vinyl- $\mathrm{Fe}_{3} \mathrm{O}_{4}$

FIGURE 1: FT-IR spectra of prepared $\mathrm{Fe}_{3} \mathrm{O}_{4}$ materials.

TABLE 1: Elemental analysis results and catalyst loading calculation.

\begin{tabular}{lcccc}
\hline Sample & $\mathrm{C}(\mathrm{wt} \%)$ & $\mathrm{H}(\mathrm{wt} \%)$ & $\mathrm{N}(\mathrm{wt} \%)$ & TEMPO loading \\
\hline Bare $\mathrm{Fe}_{3} \mathrm{O}_{4}$ & 0 & 0 & 0 & 0 \\
$\mathrm{Si}^{-} \mathrm{Fe}_{3} \mathrm{O}_{4}$ & 0 & 0 & 0 & 0 \\
Vinyl- $\mathrm{Fe}_{3} \mathrm{O}_{4}$ & 0.2 & 0.01 & 0 & 0 \\
$\mathrm{PAA}^{-} \mathrm{Fe}_{3} \mathrm{O}_{4}$ & 9.83 & 1.10 & 0 & 0 \\
TEMPO-MNPs & 32.2 & 3.55 & 3.51 & $2.5 \mathrm{mmol} / \mathrm{g}$ \\
\hline
\end{tabular}

polymer chain with respect to the carboxyl group. Previous studies have immobilized TEMPO on solid surfaces via "click" reactions, amide reduction reactions, and so forth. Recently, Karimi and coworkers showed that TEMPO was linked to the surface of the aminopropyltriethoxysilanemodified magnetic nanoparticles through amide reduction using sodium cyanoborohydrides [29-31]. Another previously known example reported by Schätz et al. [27] and Tucker-Schwartz and Garrell [28] is through "click" reaction using azide modified nanoparticles with TEMPO derivatives. However, those synthesis procedures require harsh reaction conditions or expensive catalysts. In contrast to the reports, our method requires no unstable azide compounds or toxic cyanoborohydrides substances but also increases catalyst loading to $2.5 \mathrm{mmol} / \mathrm{g}(0.1 \mathrm{mmol} / \mathrm{g}$ in the literature [28]). Hence, this synthetic route is simple and efficient.

3.2. Magnetic Properties and TEM Analysis. Transmission electron microscopy (TEM) (Figure 2) characterization of the magnetic materials indicated that bare nanoparticles were relatively uniform with an average size range of $10 \sim 30 \mathrm{~nm}$. The image also revealed that the $\mathrm{Fe}_{3} \mathrm{O}_{4}$ nanoparticles were coated with mesoporous organic compound shells. Roomtemperature magnetization curves (Figure 2(c)) showed that, after several modifications, the nanoparticle remained superparamagnetic.

3.3. Catalyst Activity and Recycling Test. With the TEMPOMNPs in hand, catalytic application and selective oxidation 


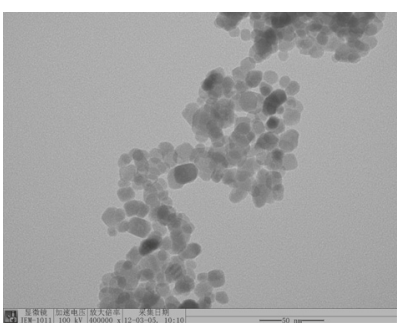

(a)

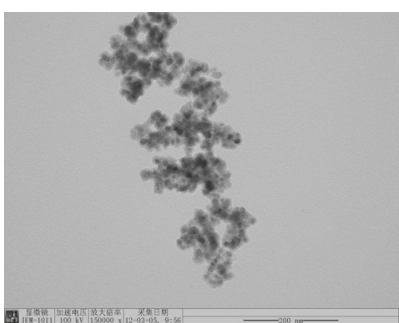

(b)

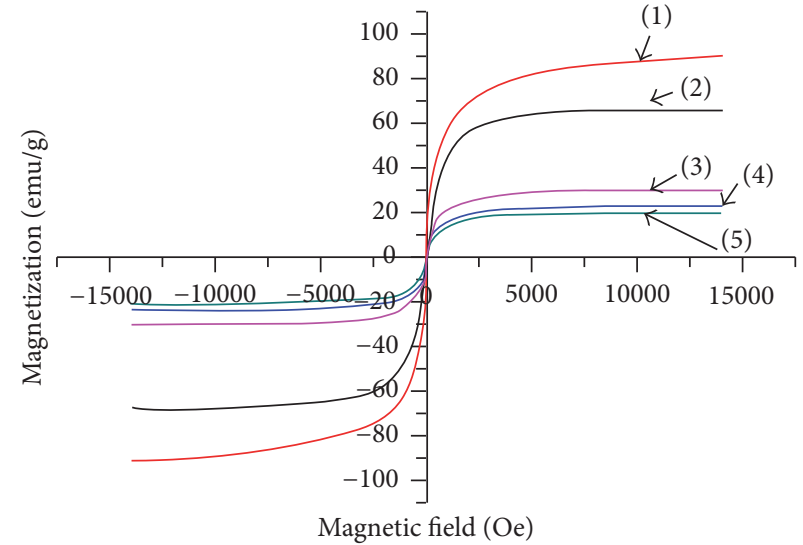
(1) $\mathrm{Fe}_{3} \mathrm{O}_{4}$
(4) $\mathrm{PAA}-\mathrm{Fe}_{3} \mathrm{O}_{4}$
(2) $\mathrm{Si}-\mathrm{Fe}_{3} \mathrm{O}_{4}$
(5) TEMPO- $\mathrm{Fe}_{3} \mathrm{O}_{4}$

(3) Vinyl- $\mathrm{Fe}_{3} \mathrm{O}_{4}$

(c)

FIgURE 2: TEM images of bare $\mathrm{Fe}_{3} \mathrm{O}_{4}$ materials (a); TEMPO-MNPs material (b); magnetization curves of the resulting $\mathrm{Fe}_{3} \mathrm{O}_{4}$ materials (c).

TABLE 2: TEMPO-MNPs mediated oxidation of alcohols to aldehydes/ketones.

\begin{tabular}{lcccc}
\hline ENTRY & Alcohol & Conversion $^{\mathrm{c}}[\%]$ & Yield $^{\mathrm{c}}[\%]$ & Selectivity $^{\mathrm{c}}[\%]$ \\
\hline $1^{\mathrm{a}}$ & Benzyl alcohol & 99 & 99 & 99.0 \\
$2^{\mathrm{a}}$ & 4-Chlorobenzyl alcohol & 98 & 98 & 98.0 \\
$3^{\mathrm{a}}$ & 4-Methoxylbenzyl alcohol & 99 & 84.8 & 85.6 \\
$4^{\mathrm{a}}$ & 4-Phenyl-2-butanol & 99 & 95.1 & 96.1 \\
$5^{\mathrm{b}}$ & Benzyl alcohol & 99 & 96.9 & 97.8 \\
$6^{\mathrm{b}}$ & 4-Chlorobenzyl alcohol & 99 & 83.1 & 84.0 \\
$7^{\mathrm{b}}$ & 4-Methoxylbenzyl alcohol & 99 & 99 & 99.0 \\
\hline
\end{tabular}

${ }^{a}$ Alcohol $(1 \mathrm{mmol})$ in DCM, potassium bromide solution $(1.0 \mathrm{M}, 1 \mathrm{~mL})$, 4-methoxyacetophenone (208.0 mg, internal standard), and TEMPO-MNPs (150 mg) were added to a round-bottom flask. The suspension was stirred in ice-water bath before addition of $\mathrm{NaClO}$ solution (0.35 M, pH 8.7, $1.05 \mathrm{eq})$. Sample aliquots were regularly taken and analyzed by GC. ${ }^{\text {b A }} 25 \mathrm{~mL}$ Schlenk-flask was charged with a solution of $1 \mathrm{mmol}$ alcohol, TEMPO-MNPs $(200 \mathrm{mg}), \mathrm{Mn}\left(\mathrm{NO}_{3}\right)_{2}(50 \%$, $120 \mathrm{mg})$, and $\mathrm{Co}\left(\mathrm{NO}_{3}\right)_{2} \cdot 6 \mathrm{H} 2 \mathrm{O}(0.4 \mathrm{mmol}, 100 \mathrm{mg})$ and in $15 \mathrm{~mL}$ of acetic acid was stirred at $40^{\circ} \mathrm{C}$ under $\mathrm{O}_{2}$ at atmospheric pressure. Sample aliquots were regularly taken and analyzed by GC. ${ }^{c}$ Conversion, yield, and selectivity were calculated according to GC or GS-MS results in the supporting information.

of alcohol were further investigated along with its recycling efficiency. There are many catalytic systems employing nitroxides as an active catalyst in cooperation with metal or metal-free cocatalysts for alcohol oxidation. They can catalyze alcohols to the corresponding aldehydes/ketones in high yield and with chemoselectivity [34, 35, 38-40]. For example, Anelli [34] first used TEMPO as a catalyst in cooperation with hypochlorite and bromide for benzyl alcohols selective oxidation. The Anelli protocol proposed by Montanari and Anelli used a two-phase $\left(\mathrm{CH}_{2} \mathrm{Cl}_{2} / \mathrm{H}_{2} \mathrm{O}\right)$ system and sodium hypochlorite as the oxidant. This convenient approach then uses bromide ion as a cocatalyst for selective oxidation of alcohols. Minisci and coworkers (Minisci protocol) used an environmentally friendly oxidant such as oxygen or air and reported aerobic oxidation catalyzed by TEMPO in cooperation with trace amounts of $\mathrm{Mn}\left(\mathrm{NO}_{3}\right)_{2}$ and $\mathrm{Co}\left(\mathrm{NO}_{3}\right)_{2}$ in acetic acid solution with excellent conversion and chemoselectivity [34]. Thus, the catalysis procedures based on TEMPO present a practical method for the selective transformation of alcohols to aldehydes/ketones.
To determine if the TEMPO-MNPs retained their catalytic activity of small molecular catalysts, we investigated catalysis test under Minisci and Anelli protocols (Table 2).

This approach catalytically transformed alcohols to the corresponding carbonyl compounds (Table 2) using the insoluble magnetically supported TEMPO. Under the Anelli oxidation protocol, primary benzyl alcohols were quickly and efficiently converted into the aromatic aldehydes (5 $\mathrm{min}$ ) (Table 2, entries 1-3). Secondary alcohols can also be transformed to ketones almost as quickly as the benzyl alcohol (entry 4, Table 2) with TEMPO catalysis.

Analogously, aldehydes were prepared by the selective transformation of primary alcohols under mild conditions proposed by Minisci; the yield was good. The catalytic activity of supported TEMPO materials combining cocatalysts $\mathrm{Mn}(\mathrm{II})-\mathrm{Co}(\mathrm{II})$ nitrates was also applied to the aerobic oxidation of alcohols/aldehydes with excellent yields (entries 5-7, Table 2). The catalytic oxidation experiments under two wellknown procedures showed that the organic catalyst TEMPO was successfully immobilized on the nanocomposite material 


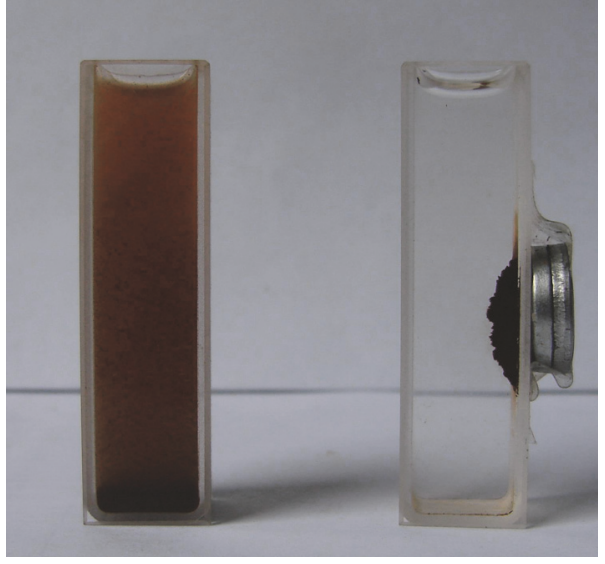

(a)

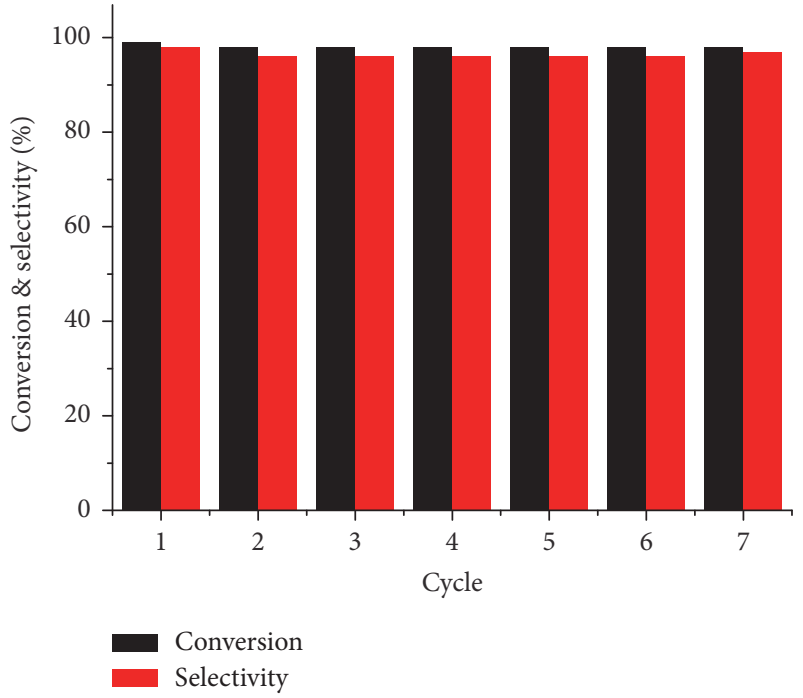

(b)

FIGURE 3: (a) Image for the magnetic separation of the nanoparticles in the Montanari oxidation of benzyl alcohol. (b) Recyclability of TEMPO supported on nanocomposite particles in the Montanari oxidation of benzyl alcohol.

while still maintaining good catalytic ability throughout the synthesis process.

Encouraged by these results, we next investigated TEMPOMNPs recyclability and reusability via oxidation of 4-methoxylbenzyl alcohol under the Montanari oxidation procedure. TEMPO-MNPs (150 mg scale) recyclability was achieved via separation through successive magnetic decantation as shown in Figure 3(a). After washing thoroughly with $\mathrm{CH}_{2} \mathrm{Cl}_{2}$, acetone, and $\mathrm{H}_{2} \mathrm{O}$, successively, TEMPO-MNPs continued in the next run. The recycling and reuse demonstrated the efficiency of magnetic separation of the prepared material. The reusability of TEMPO-supported material was illustrated by GC conforming 4-methoxylbenzyl alcohol conversion in the 7 th cycle. Oxidation conversion of 7 th run was $97 \%$ after a reaction time of $5 \mathrm{~min}$ and with a selectivity of $>96 \%$ (Figure 3(b), cycle 7). GC-MS analysis of the separated supernatant (as shown in Figure 3(a)) indicated no trace of TEMPO residue during oxidation. TEMPO remained stable under variety of catalytic environments despite being attached to a poly(acrylic acid) chain through an ester bond TEMPO-MNPs.

\section{Conclusion}

In conclusion, we developed a novel method to prepare magnetic polymer nanoparticles as an ideal support material for immobilizing organic catalysts $2,2^{\prime}, 6,6^{\prime}$-tetramethylpiperidinyl-1-oxy (TEMPO). According to characterization results, acrylic acid is efficiently polymerized onto the silicacoated magnetic particles by applying inverse emulsion polymerization, and TEMPO is immobilized onto the particles. The synthesis procedures are simple and facile. They efficiently immobilized TEMPO. TEMPO-MNPs still retained the advantages of magnetic materials (simple separation with no mechanical loss) and showed excellent catalytic capabilities in alcohols for selective oxidation under the Anelli and Minisci procedures. The recyclability study on TEMPO-MNPs shows neither significant loss of activity nor selectivity dropping after 7 consecutive cycles.

\section{Additional Points}

Supporting Information. Gas chromatography (GC) and gas chromatography-mass spectrometry (GC-MS) results for catalysis experiments are included in the supporting information.

\section{Conflicts of Interest}

The authors declare that there are no conflicts of interest regarding the publication of this paper.

\section{Acknowledgments}

This work was financially supported by the National Nature Science Foundation of China (Grant nos. 51403041 and 51641302) and China Postdoctoral Science Foundation (2014M562183). The authors thank LetPub (www.letpub.com) for its linguistic assistance during the preparation of this manuscript.

\section{References}

[1] L. L. Chng, N. Erathodiyil, and J. Y. Ying, "Nanostructured catalysts for organic transformations," Accounts of Chemical Research, vol. 46, no. 8, pp. 1825-1837, 2013. 
[2] V. Polshettiwar, R. Luque, A. Fihri, H. B. Zhu, M. Bouhrara, and J.-M. Basset, "Magnetically recoverable nanocatalysts," Chemical Reviews, vol. 111, no. 5, pp. 3036-3075, 2011.

[3] R. B. N. Baig and R. S. Varma, "Magnetically retrievable catalysts for organic synthesis," Chemical Communications, vol. 49, no. 8, pp. 752-770, 2013.

[4] R. B. N. Baig and R. S. Varma, "Copper on chitosan: a recyclable heterogeneous catalyst for azide-alkyne cycloaddition reactions in water," Green Chemistry, vol. 15, no. 7, pp. 1839-1843, 2013.

[5] M. Bradshaw, J. Zou, L. Byrne, K. Swaminathan Iyer, S. G. Stewart, and C. L. Raston, "Pd(ii) conjugated chitosan nanofibre mats for application in Heck cross-coupling reactions," Chemical Communications, vol. 47, no. 45, pp. 12292-12294, 2011.

[6] P. Kasaplar, C. Rodríguez-Escrich, and M. A. Pericàs, "Continuous flow, highly enantioselective Michael additions catalyzed by a PS-supported squaramide," Organic Letters, vol. 15, no. 14, pp. 3498-3501, 2013.

[7] Y. Li, Y. Wu, Q. Xu et al., "Facile and controllable synthesis of polystyrene/palladium nanoparticle@polypyrrole nanocomposite particles," Polymer Chemistry, vol. 4, no. 17, pp. 46554662, 2013.

[8] G. Strappaveccia, D. Lanari, D. Gelman et al., "Efficient synthesis of cyanohydrin trimethylsilyl ethers via 1,2-chemoselective cyanosilylation of carbonyls," Green Chemistry, vol. 15, no. 1, pp. 199-204, 2013.

[9] C. Yang, C.-H. Choi, C.-S. Lee, and H. Yi, "A facile synthesis-fabrication strategy for integration of catalytically active viralpalladium nanostructures into polymeric hydrogel microparticles via replica molding," ACS Nano, vol. 7, no. 6, pp. 5032-5044, 2013.

[10] D. P. Hickey, R. D. Milton, D. Chen, M. S. Sigman, and S. D. Minteer, "TEMPO-modified linear poly(ethylenimine) for immobilization-enhanced electrocatalytic oxidation of alcohols," ACS Catalysis, vol. 5, no. 9, pp. 5519-5524, 2015.

[11] M. V. Khedkar, T. Sasaki, and B. M. Bhanage, "Immobilized palladium metal-containing ionic liquid-catalyzed alkoxycarbonylation, phenoxycarbonylation, and aminocarbonylation reactions," ACS Catalysis, vol. 3, no. 3, pp. 287-293, 2013.

[12] Z.-L. Shen, H.-L. Cheong, Y.-C. Lai, W.-Y. Loo, and T.-P. Loh, "Application of recyclable ionic liquid-supported imidazolidinone catalyst in enantioselective Diels-Alder reactions," Green Chemistry, vol. 14, no. 9, pp. 2626-2630, 2012.

[13] H. Zhao, W. Hao, Z. Xi, and M. Cai, "Palladium-catalyzed crosscoupling of $\mathrm{PhSeSnBu3}$ with aryl and alkyl halides in ionic liquids: a practical synthetic method of diorganyl selenides," New Journal of Chemistry, vol. 35, no. 11, pp. 2661-2665, 2011.

[14] K. Arya, U. C. Rajesh, and D. S. Rawat, "Proline confined FAU zeolite: heterogeneous hybrid catalyst for the synthesis of spiroheterocycles via a mannich type reaction," Green Chemistry, vol. 14, no. 12, pp. 3344-3351, 2012.

[15] M. Genelot, N. Villandier, A. Bendjeriou, P. Jaithong, L. Djakovitch, and V. Dufaud, "Palladium complexes grafted onto mesoporous silica catalysed the double carbonylation of aryl iodides with amines to give $\alpha$-ketoamides," Catalysis Science and Technology, vol. 2, no. 9, pp. 1886-1893, 2012.

[16] S. Wang, Q. Zhao, H. Wei et al., "Aggregation-free gold nanoparticles in ordered mesoporous carbons: Toward highly active and stable heterogeneous catalysts," Journal of the American Chemical Society, vol. 135, no. 32, pp. 11849-11860, 2013.

[17] A. Machado, M. H. Casimiro, L. M. Ferreira et al., "New method for the immobilization of nitroxyl radical on mesoporous silica," Microporous and Mesoporous Materials, vol. 203, pp. 63-72, 2015.
[18] N. Mittal, G. M. Nisola, J. G. Seo, S.-P. Lee, and W.-J. Chung, "Organic radical functionalized SBA-15 as a heterogeneous catalyst for facile oxidation of 5-hydroxymethylfurfural to 2,5diformylfuran," Journal of Molecular Catalysis A: Chemical, vol. 404-405, pp. 106-114, 2015.

[19] D. T. Genna, A. G. Wong-Foy, A. J. Matzger, and M. S. Sanford, "Heterogenization of homogeneous catalysts in metal-organic frameworks via cation exchange," Journal of the American Chemical Society, vol. 135, no. 29, pp. 10586-10589, 2013.

[20] A. Pourjavadi, S. H. Hosseini, M. Doulabi, S. M. Fakoorpoor, and F. Seidi, "Multi-Layer functionalized poly(ionic liquid) coated magnetic nanoparticles: highly recoverable and magnetically separable brønsted acid catalyst," ACS Catalysis, vol. 2, no. 6, pp. 1259-1266, 2012.

[21] S. Wang, Z. Zhang, B. Liu, and J. Li, "Silica coated magnetic $\mathrm{Fe} 3 \mathrm{O} 4$ nanoparticles supported phosphotungstic acid: a novel environmentally friendly catalyst for the synthesis of 5-ethoxymethylfurfural from 5-hydroxymethylfurfural and fructose," Catalysis Science \& Technology, vol. 3, no. 8, pp. 2104-2112, 2013.

[22] J. Zhu, P.-C. Wang, and M. Lu, "Synthesis of novel magnetic silica supported hybrid ionic liquid combining TEMPO and polyoxometalate and its application for selective oxidation of alcohols," RSC Advances, vol. 2, no. 22, pp. 8265-8268, 2012.

[23] J. Lu and P. H. Toy, "Organic polymer supports for synthesis and for reagent and catalyst immobilization," Chemical Reviews, vol. 109, no. 2, pp. 815-838, 2009.

[24] Q. Zhang, J. Kang, B. Yang, L. Zhao, Z. Hou, and B. Tang, "Immobilized cellulase on $\mathrm{Fe}_{3} \mathrm{O}_{4}$ nanoparticles as a magnetically recoverable biocatalyst for the decomposition of corncob," Chinese Journal of Catalysis, vol. 37, no. 3, pp. 389-397, 2016.

[25] Q. Cao, L. M. Dornan, L. Rogan, N. L. Hughes, and M. J. Muldoon, "Aerobic oxidation catalysis with stable radicals," Chemical Communications, vol. 50, no. 35, pp. 4524-4543, 2014.

[26] S. Wertz and A. Studer, "Nitroxide-catalyzed transition-metalfree aerobic oxidation processes," Green Chemistry, vol. 15, no. 11, pp. 3116-3134, 2013.

[27] A. Schätz, R. N. Grass, W. J. Stark, and O. Reiser, “TEMPO supported on magnetic C/Co-nanoparticles: a highly active and recyclable organocatalyst," Chemistry-A European Journal, vol. 14, no. 27, pp. 8262-8266, 2008.

[28] A. K. Tucker-Schwartz and R. L. Garrell, "Simple preparation and application of TEMPO-coated $\mathrm{Fe} 3 \mathrm{O} 4$ superparamagnetic nanoparticles for selective oxidation of alcohols," Chemistry-A European Journal, vol. 16, no. 42, pp. 12718-12726, 2010.

[29] B. Karimi and E. Farhangi, "A highly recyclable magnetic coreshell nanoparticle-supported TEMPO catalyst for efficient metal- and halogen-free aerobic oxidation of alcohols in water," Chemistry - A European Journal, vol. 17, no. 22, pp. 6056-6060, 2011.

[30] B. Karimi and E. Farhangi, "One-pot oxidative passerini reaction of alcohols using a magnetically recyclable TEMPO under metal- and halogen-free conditions," Advanced Synthesis and Catalysis, vol. 355, no. 2-3, pp. 508-516, 2013.

[31] B. Karimi, H. M. Mirzaei, and E. Farhangi, " $\mathrm{Fe}_{3} \mathrm{O}_{4} @ \mathrm{SiO}_{2}$ TEMPO as a magnetically recyclable catalyst for highly selective aerobic oxidation of 5-hydroxymethylfurfural into 2,5-diformylfuran under metal-and halogen-free conditions," ChemCatChem, vol. 6, no. 3, pp. 758-762, 2014.

[32] Z. Zheng, J. L. Wang, M. Zhang, L. Xu, and J. B. Ji, "Magnetic polystyrene nanosphere immobilized TEMPO: a readily prepared, highly reactive and recyclable polymer catalyst in the selective oxidation of alcohols," Chem CatChem, vol. 5, no. 1, pp. 307-312, 2013. 
[33] M. Benaglia, A. Puglisi, and F. Cozzi, "Polymer-supported organic catalysts," Chemical Reviews, vol. 103, no. 9, pp. 3401-3429, 2003.

[34] P. L. Anelli, C. Biffi, F. Montanari, and S. Quici, "Fast and selective oxidation of primary alcohols to aldehydes or to carboxylicacids and of secondary alcohols to ketones mediated by oxoammonium salts under two-phase conditions," Journal of Organic Chemistry, vol. 52, no. 12, pp. 2559-2562, 1987.

[35] A. Cecchetto, F. Fontana, F. Minisci, and F. Recupero, "Efficient $\mathrm{Mn}-\mathrm{Cu}$ and $\mathrm{Mn}$-Co-TEMPO-catalysed oxidation of alcohols into aldehydes and ketones by oxygen under mild conditions," Tetrahedron Letters, vol. 42, no. 38, pp. 6651-6653, 2001.

[36] Y.-F. Huang, Y.-F. Wang, and X.-P. Yan, "Amine-functionalized magnetic nanoparticles for rapid capture and removal of bacterial pathogens," Environmental Science and Technology, vol. 44, no. 20, pp. 7908-7913, 2010.

[37] D. Wang, L. Salmon, J. Ruiz, and D. Astruc, "A recyclable ruthenium(ii) complex supported on magnetic nanoparticles: a regioselective catalyst for alkyne-azide cycloaddition," Chemical Communications, vol. 49, no. 62, pp. 6956-6958, 2013.

[38] P. Gamez, I. W. C. E. Arends, J. Reedijk, and R. A. Sheldon, "Copper(II)-catalysed aerobic oxidation of primary alcohols to aldehydes," Chemical Communications, vol. 9, no. 19, pp. 24142415, 2003.

[39] A. M. Khenkin and R. Neumann, "Oxygen transfer from sulfoxides: Selective oxidation of alcohols catalyzed by polyoxomolybdates," Journal of Organic Chemistry, vol. 67, no. 20, pp. 7075-7079, 2002.

[40] M. F. Semmelhack, C. R. Schmid, D. A. Cortes, and C. S. Chou, "Oxidation of alcohols to aldehydes with oxygen and cupric ion, mediated by nitrosonium ion," Journal of the American Chemical Society, vol. 106, no. 11, pp. 3374-3376, 1984. 

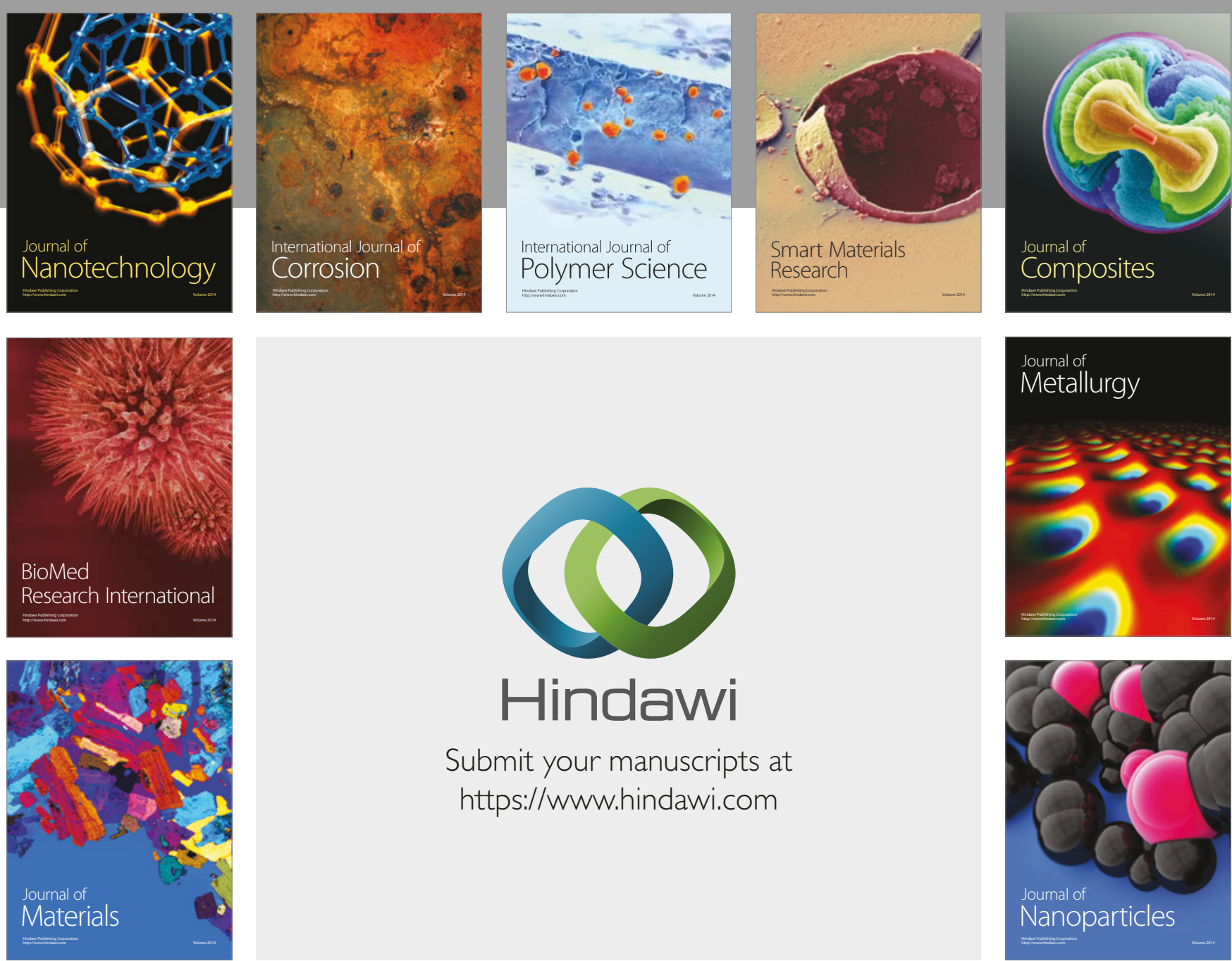

\section{Hindawi}

Submit your manuscripts at

https://www.hindawi.com
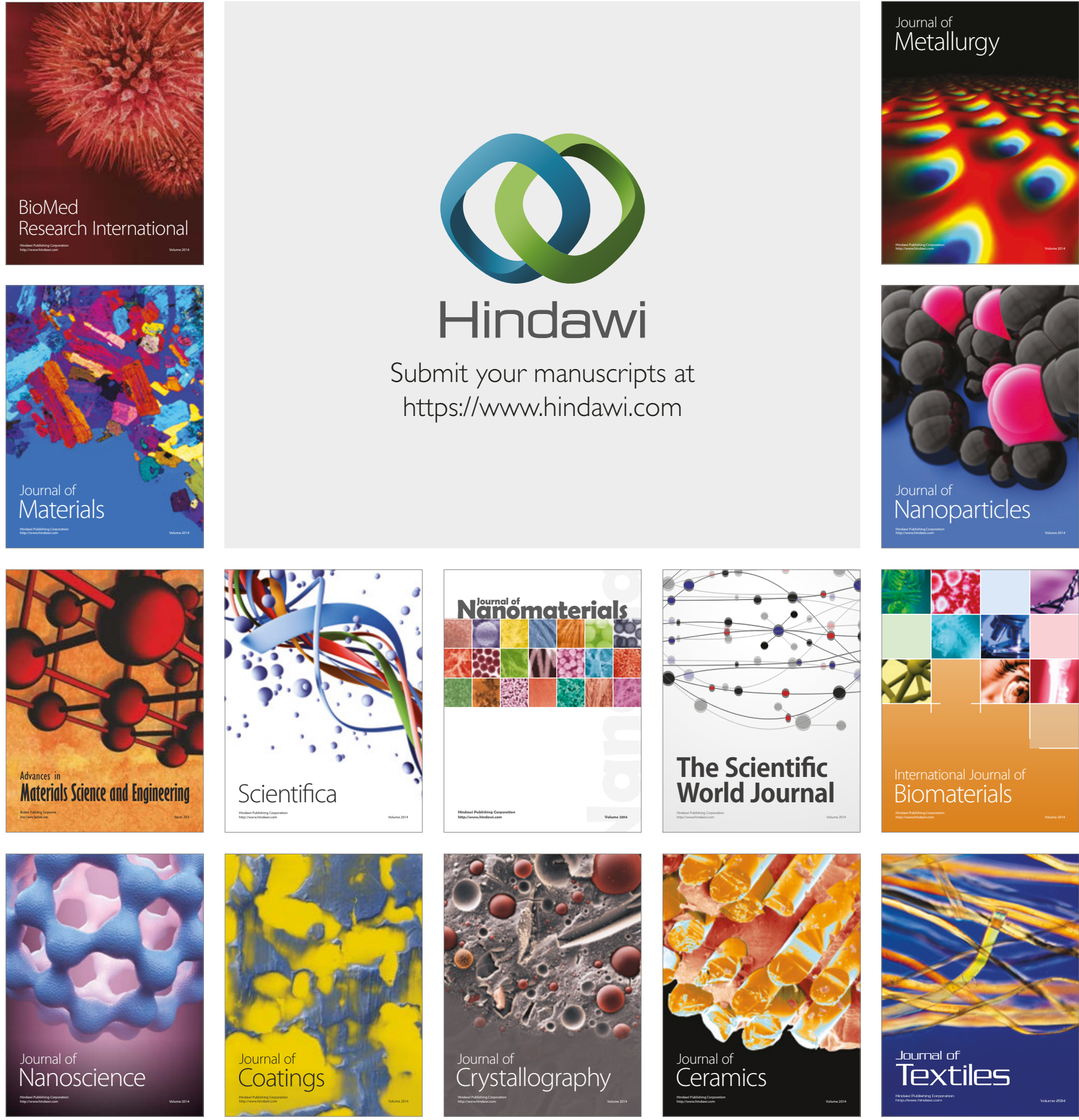

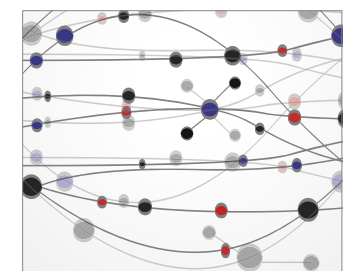

The Scientific World Journal
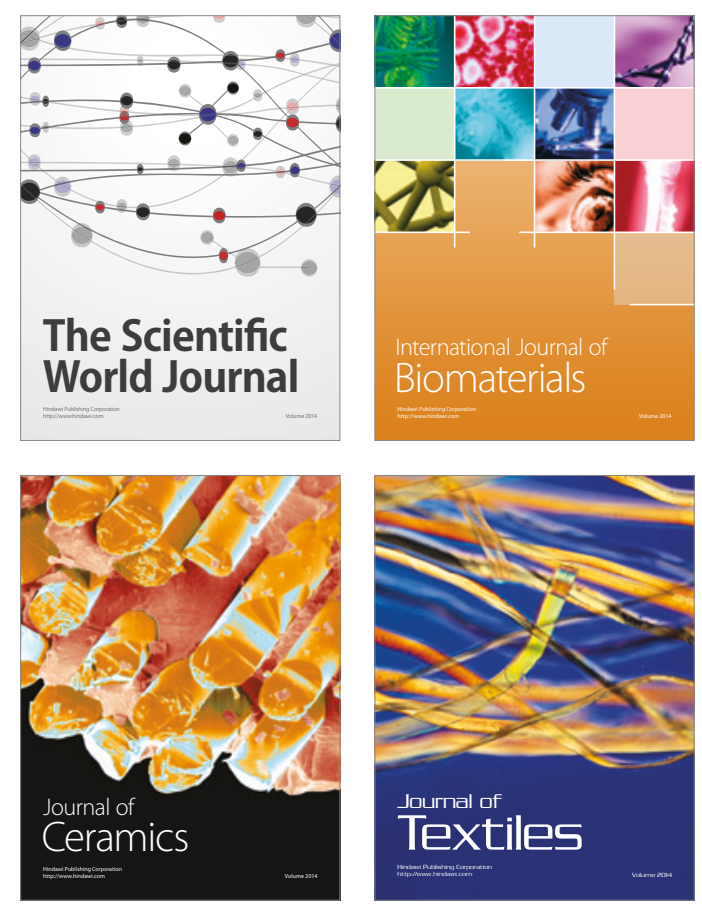